\title{
A numerical study on horizontal hydraulic fracture
}

\author{
J. Zhang $\cdot$ F. J. Biao $\cdot$ S. C. Zhang $\cdot$ \\ X. X. Wang
}

Received: 4 November 2010/ Accepted: 23 November 2011/Published online: 21 December 2011

(C) The Author(s) 2011. This article is published with open access at Springerlink.com

\begin{abstract}
A 3D non-linear fluid-solid coupling model for horizontal fracture of vertical well was established with the ABAQUS code. The wellbore, cement casing, perforation, pay layer and barriers were included in the model. Fluidsolid coupling elements were used to describe the behavior of formation stress-seepage flow coupling; pore pressure cohesive elements were employed to simulate the process of fracture initiation and propagation in formation. A typical horizontal fracturing process of a vertical well of Daqing Oilfield, China was simulated with the model. All the concerned parameters in simulation were taken from the field measurements. The simulated bottom-hole pressure evolution is consistent with the data measured from the field. The configurations of the fracture and porous pressure distributions in the fracture are presented and discussed.
\end{abstract}

Keywords Fracture propagation - Horizontal fracture . Non-linear model · Fluid-solid coupling · Cohesive element

\section{Introduction}

Hydraulic fracturing has been one of the most frequently implemented techniques for stimulating production of oil/ gas reservoirs for several decades (Sneddon 1946).

J. Zhang $(\bowtie) \cdot$ S. C. Zhang

School of Petroleum Engineering,

China University of Petroleum, Beijing 102200, China

e-mail: zhj718@126.com

F. J. Biao $\cdot$ X. X. Wang

Department of Modern Mechanics,

University of Science and Technology of China,

Hefei 230026, China
Common water-based fracturing fluid with chemical additives is pumped at high rate and pressure into the formation during hydraulic fracturing process. When the pumping pressure exceeds the strength of the formation rock, fractures are induced and propagated into the formation, and then the propping agent is pumped into the fractures to keep them from closing after pumping pressure is released. Therefore, a man-made passage with high conductivity is constructed and hydrocarbon can flow into the well from the low-permeability formation (Economides and Nolte 2000).

Horizontal or vertical fractures of vertical wells may be developed depending on the factors such as depth of the well, distributions of in situ stresses and lithological parameters in formation. Fractures usually propagate perpendicular to the minimum principal stress. At shallow depths, the minimum principal stresses correspond to the overburden; therefore, horizontal fractures are constructed (Settari and Michael 1986). Numerical simulations of vertical fractures have been studied by many authors (Morales and Abou-Sayed 1989; Boone and Detournay 1990) and reviewed (Fragachan et al. 1993). Most of the models fall into pseudo 3-dimension (p-3D) and are successful in design and performances of hydraulic fractures. Results of microseismic imaging show that fracture orientation is related to thrust fault near the wellbore. A horizontal fracture could be formed below the fault (Maxwell et al. 2009). Engineering practices of Daqing Oilfield, China show that many of the hydraulic fractures are horizontal in areas of remained reserves. Significant restimulation could be gained from horizontal hydraulic fracturing (Schneider et al. 2007), but studies on mechanism and numerical simulation of horizontal fractures are rarely founded in the literature to our knowledge. A quasi static radial model of horizontal fracture was proposed

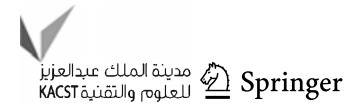


(Sneddon 1946). The relationship among width, radius and pressure in the fracture was presented, but flow and variation of pressure in the fracture as well as leak off across the fracture walls were not considered in the model. Interference among horizontal fractures of multi-pay layer reservoirs was studied (Zhang and Zhang 2004). However in the model plan, strain assumption was made, the length of the fracture was pointed to be a fixed value and the loading applied on the fracture walls distributed force but not fluid pressure.

In the present paper, a 3D non-linear fluid-solid coupling model for horizontal fracture was established with the ABAQUS code. The wellbore, cement casing, pay layer, barriers and perforations were included in the model. Fluidsolid coupling elements were used to describe the behavior of formation stress-seepage flow coupling; pore pressure cohesive elements based on damage mechanics were employed to simulate the process of fracture initiation and propagation. A typical horizontal fracturing process of a vertical well in the Daqing Oilfield, China was simulated with the model. The simulated results show that the evolution of the bottom-hole pressure matches the data measured from the field very well. The correctness and reliability of the proposed model is validated. The horizontal fracture/configurations as well as porous pressure distributions in the fracture are also presented and discussed.

\section{Mathematical physics model}

Hydraulic fracturing can be regarded as two physical processes: one is the fluid field in the well and fractures; the other is the stress-seepage flow coupling field in formation. The two processes are connected by fluid exchange and interaction of pressure on the fracture walls.

Governing equations of stress-seepage flow coupling field in formation

In the current configuration, the equilibrium equation of porous formation can be written as (Zienkiewicz and Taylor 2005)

$\int_{v}\left(\bar{\sigma}-p_{w} I\right) \delta \dot{\varepsilon} \mathrm{d} V=\int_{s} t \cdot \delta v \mathrm{~d} S+\int_{v} f \cdot \delta v \mathrm{~d} V$

where $\bar{\sigma}, p_{\mathrm{w}}, \delta \dot{\varepsilon}, \delta \boldsymbol{v}, \mathbf{t}$ and $\mathbf{f}$ are the effective stress matrix, pore pressure, virtual strain rate matrix, virtual velocity vector, surface force vector and volume force vector, respectively.

The effective stress couples solid deformation with fluid flow by the following formulation (Economides and Nolte 2000)

$\bar{\sigma}=\sigma-p_{w} I$

where $\sigma$ is the stress caused by solid deformation.
Continuity equation of seepage flow considering large deformation of porous formation is (Malvern 1969)

$\frac{1}{J} \frac{\partial}{\partial t}\left(J \rho_{w} n_{w}\right)+\frac{\partial}{\partial x} \cdot\left(\rho_{w} n_{w} v_{w}\right)=0$

where $J$ and $x$ are the rate of volume dilatation and space vector, respectively; $\rho_{\mathrm{w}}, n_{\mathrm{w}}$ and $v_{\mathrm{w}}$ are fluid density, porosity and seepage velocity, respectively.

The kinetics equation is the Darcy's law in the following form (Marino and Luthin 1982)

$v_{w}=-\frac{1}{n_{w} g \rho_{w}} k \cdot\left(\frac{\partial p_{w}}{\partial x}-\rho_{w} g\right)$

where $\boldsymbol{k}$ and $\boldsymbol{g}$ are permeability matrix and gravity acceleration vector, respectively.

Flow equations of fluid in fractures

The flow of proppant-laden fluid in the fracture is assumed to be incompressible Newtonian fluid and can be resolved as a tangential component along the cohesive element walls and a normal component across the cohesive element walls, respectively. The tangential one can be expressed as (Dean and Schmidt 2008)

$q=\frac{t^{3}}{12 \mu} \nabla p$

where $q, t, \mu$ and $p$ are the vector of volume flow rate along the cohesive element walls per tangential unit length, the opening thickness of the cohesive elements, the coefficient of viscosity of fracturing liquid in the cohesive elements and fluid pressure in the cohesive elements, respectively.

The normal component represents speed of fluid flowing in or out the walls of the cohesive elements. That is the filtration rate of fracturing liquid in engineering and expressed as (Hagoort et al. 1978)

$\left\{\begin{array}{r}q_{\mathrm{t}}=c_{\mathrm{t}}\left(p_{\mathrm{i}}-p_{\mathrm{t}}\right) \\ q_{\mathrm{b}}=c_{\mathrm{b}}\left(p_{\mathrm{i}}-p_{\mathrm{b}}\right)\end{array}\right.$

where $q_{\mathrm{t}}$ and $q_{\mathrm{b}}$ are the volume flow rate across the top and bottom walls of the cohesive elements, respectively; $c_{\mathrm{t}}$ and $c_{\mathrm{b}}$ are the filtration coefficients of the top and bottom walls of the cohesive elements, respectively; $p_{\mathrm{t}}$ and $p_{\mathrm{b}}$ are the pore pressures at the top and bottom walls, respectively; and $p_{\mathrm{i}}$ is the fluid pressure along the middle plan of cohesive elements.

Damage model of cohesive element

Initiation and extension of fracture are simulated with the cohesive element. The damage initiation of the formation can be expressed by the following criterion formula in cohesive element (Camanho and Dávila 2002) 
$\left\{\frac{\left\langle\sigma_{\mathrm{n}}\right\rangle}{\sigma_{\mathrm{n}}^{0}}\right\}^{2}+\left\{\frac{\sigma_{\mathrm{s}}}{\sigma_{\mathrm{s}}^{0}}\right\}^{2}+\left\{\frac{\sigma_{\mathrm{t}}}{\sigma_{\mathrm{t}}^{0}}\right\}^{2}=1$

where $\sigma_{\mathrm{n}}$ is the normal stress, $\sigma_{\mathrm{s}}$ and $\sigma_{\mathrm{t}}$ are the tangential stresses, and $\sigma_{\mathrm{n}}^{0}$ is the intensity of tension of formation. $\sigma_{s}^{0}$ and $\sigma_{t}^{0}$ are the threshold stresses of tangential damage. The symbol $<>$ denotes that only tensile stress could make the cohesive element damaged.

For simulating degeneration of elastic modulus of cohesive element after damage initiated as expressed in Eq. (7), the following linear damage evolution rule is adopted.

$E=(1-d) \times E^{0}$

where $E^{0}$ and $E$ are the initial element elastic modulus (without damage) and damaged element elastic modulus, respectively, and $d$ is the damage factor which can be calculated with the following formula (Turon et al. 2006)

$d=\int_{\delta_{m}^{a}}^{\delta_{m}^{f}} \frac{\sigma_{\mathrm{eff}} d \delta}{G^{C}-G_{0}}$

where $\sigma_{\text {eff }}$ and $\delta$ are the effective tensile stress and corresponding strain, respectively. $G_{0}$ and $G^{C}$ are the elastic strain energy at damage initiation and at breaking of the element, respectively.

\section{Finite element discretization and the simulation model}

The deformation, strain, stress and the fluid seepage in the formation during hydraulic fracturing are described by Eqs. (1)-(5) which couple each other and are highly non-linear. A corresponding incremental finite element formula was derived in detail (Zhang et al. 2010). The final expression of the formula and the meanings of the variables in the formula are listed in the following form

$$
\begin{gathered}
{\left[\begin{array}{cc}
K & L \\
H+\alpha M \Delta t & S+\alpha N \Delta t
\end{array}\right]\left\{\begin{array}{c}
\Delta(u)^{n+1} \\
\Delta\left(p_{w}\right)^{n+1}
\end{array}\right\}} \\
=\left\{\begin{array}{c}
F \\
V-M(u)^{n}-N\left(p_{w}\right)^{n}
\end{array}\right\} \Delta t
\end{gathered}
$$

where $\Delta(\boldsymbol{u})^{n+1}$ and $\Delta\left(\boldsymbol{p}_{\mathbf{w}}\right)^{n+1}$ are incremental displacements and incremental pore pressure, respectively. The submatrices in the left side of the formula and load vector in the right side are complicatedly related to the current deformation and pressure.

The incremental finite element formula is solved with the well-known Newton-Raphson iteration scheme. The tolerance value of iteration residual in each increment is set as $0.5 \%$ of the force.

The eight node hexahedron elements are used for describing deformation and seepage in formation. There are four nodal unknowns at each node, i.e., incremental displacements in three directions of the Cartesian coordinate system and incremental pore pressure. The plan cohesive elements with six nodal pairs are adopted to simulate the fracture initiation and propagation.

A typical vertical oil well in Daqing Oilfield, China is simulated with the proposed model. The wellbore, cement casing, pay layer, barriers and perforations were included in the model as shown in Fig. 1. The depth of the artificial bottom hole is $1,230.2 \mathrm{~m}$. A fracturing pipe is used to produce pipe string with $62 \mathrm{~mm}$ interior diameter. The outside diameter and thickness of the wellbore are 140 and $7.72 \mathrm{~mm}$, respectively. The outside diameter of the cement casing is $200 \mathrm{~mm}$; the outside diameter and length of the perforation are 11 and $786 \mathrm{~mm}$, respectively. The thickness of the pay layer is $5.9 \mathrm{~m}$. The pay layer is interlinked by the top and bottom barriers, respectively.

In situ stresses along $X, Y$ and $Z$ axes are 23, 26 and $20 \mathrm{MPa}$, respectively. The density of the reservoir is $2,200 \mathrm{~kg} / \mathrm{m}^{3}$. The initial porosity and initial porous pressure of formation are 0.20 and $10.8 \mathrm{MPa}$, respectively. The permeability of the reservoir is $0.069 \mu \mathrm{m}^{2}$. The normal and tangential damage threshold stresses of cohesive elements are $2.5 \mathrm{MPa}$. The proppant is quartz sand. Other related parameters are listed in Table 1. In simulation, the slurry is equivalent to a liquid with viscosity related to proppant concentration as (Adachi et al. 2007)

$\mu=0.1 \times(1-c / 0.65)^{-1.7}$

where $\mu$ is the viscosity of the equivalent fluid, and $c$ is the volume concentration of the proppant. All the concerned parameters are provided from the oil field.

The sizes of the simulation model along $X, Y$ and $Z$ axes are 300,300 and $100 \mathrm{~m}$, respectively. The $X Y$ plane is located in the middle of the pay layer and $Z$ axis is toward up. All normal displacements are restricted and pore pressure kept at $10.86 \mathrm{MPa}$ on the model boundaries during the whole fracturing process. The finite element mesh includes 72,800 elements and 116,688 nodes. Figure 2 depicts the sketch of the finite element mesh.

The simulation of the fracturing process was carried out with the field operation curves including liquid injection rate, proppant concentration and injection duration as shown in Fig. 3. The major controllable quantities in hydraulic fracture practice are the injected pad liquid rate and proppant, which are pumped into the wellbore from their storage tanks. The quantities in operation are measured and recorded by instruments connected in a computer van. It can be seen that the measured wellhead pressure increases sharply before the break point due to the hardness of fracture initiation. The rock is damaged and the fracture propagates steadily after that point, the pressure decreases and then almost keeps unchanged. Additionally as the 
Fig. 1 Local schematic of the model near the well hole

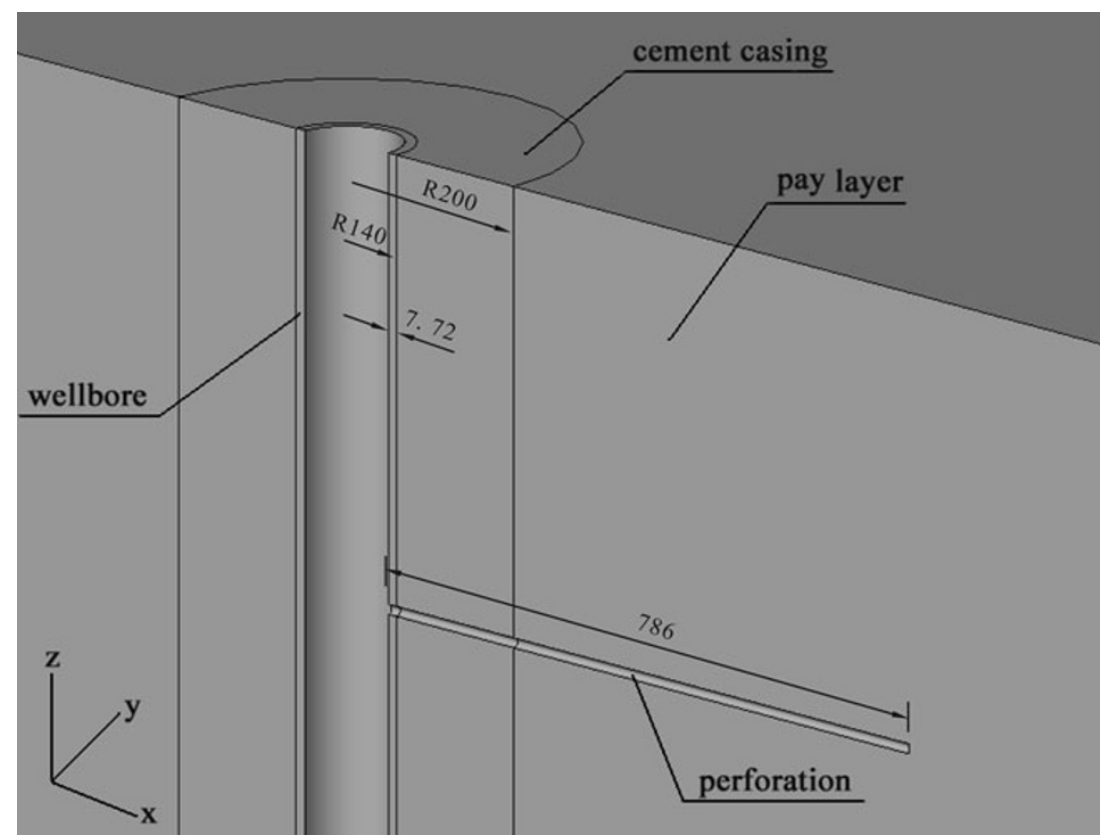

\section{Simulation results and discussions}

Table 1 Formation lithological parameters

\begin{tabular}{lllll}
\hline & $\begin{array}{l}\text { Elastic } \\
\text { modulus } \\
(\mathrm{GPa})\end{array}$ & $\begin{array}{l}\text { Poisson's } \\
\text { ration }\end{array}$ & $\begin{array}{l}\text { Permeability } \\
(\mathrm{mD})\end{array}$ & $\begin{array}{l}\text { Specific weight } \\
\text { of fluid }\left(\mathrm{N} \mathrm{m}^{-3}\right)\end{array}$ \\
\hline Pay zones & 35.0 & 0.2 & 68.6 & 8,624 \\
Barriers & 41.4 & 0.25 & $6.86 \mathrm{e}-3$ & 8,624 \\
\hline
\end{tabular}

proppant is injected into the fracture, the hydrostatic head increases while the perforation friction loss decreases. These factors also cause the wellhead pressure to decrease. The pad fluid without proppant is injected in the first several minutes of fracturing and then the proppant is added; the concentration increases in a step form. Therefore, a time lag between proppant concentration and wellhead pressure increase is induced as shown in Fig. 3.
The direct output of numerical simulation is the time history of pressure at the bottom hole, but what is measured in engineering performance usually is the wellhead pressure on the ground. The pressure values at the bottom hole and on ground can be related by considering pressure lose due to friction on way (Lord and McGowen 1986; Deeg 1999) and perforation expansion (Willingham et al. 1993), as well as the hydrostatic head in the well column. Therefore, the wellhead pressure evolution measured on ground can be transformed to the corresponding bottom-hole pressure, by considering the above factors, and then compared to the simulation obtained bottom-hole pressure.

Figure 4 presents the curves of pressure at the bottom hole from numerical simulation and the corresponding field
Fig. 2 Sketch of the finite element mesh

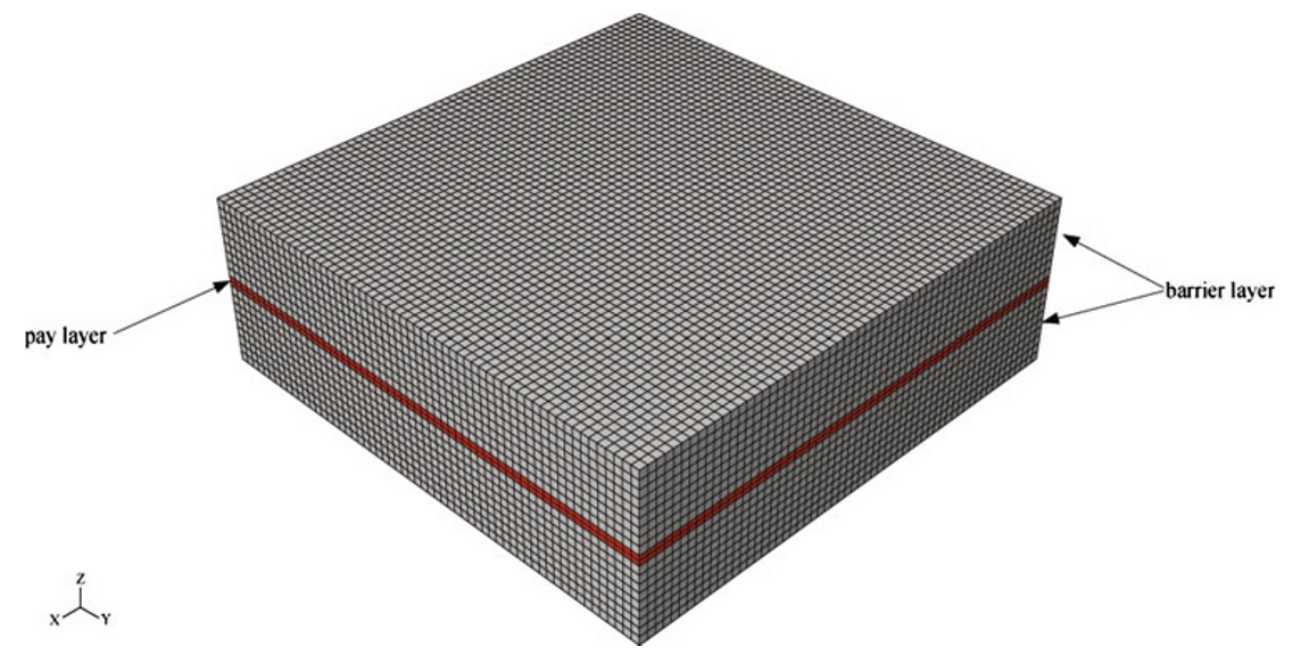




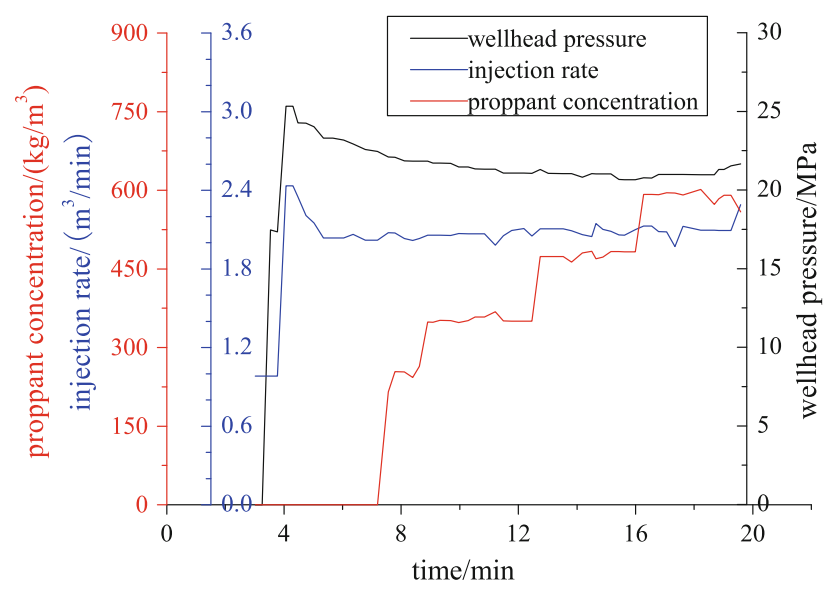

Fig. 3 Field operational curves during fracturing

measured data. The breakdown pressures from the field measurement and numerical simulation are 27.7 and 28.2 MPa, respectively. It is clear that the simulation result is consistent with what of the field-measured one. Validation of the proposed model is approved. It can be seen that the curve of the simulated bottom-hole pressure oscillates around the field-measured curve closely. The zigzag increase and decrease of the simulation curve corresponds to the halt and sequel in the fracture propagation process step by step. Stage fracturing was performed; therefore, the pressure lose due to perforation expansion is very small in the order of $\mathrm{KPa}$ and can be negligible. The pressure lose due to on-way friction was about 7-8 $\mathrm{MPa}$, because the delivery capacity was stable during the fracturing process. Figure 4 also shows that the hydrostatic head in the well column steps up as the density of slurry (the concentration of proppant) increases. It is noted from Fig. 3 that the pressure rises much more quickly at the initial stage of fracturing in simulation (about 2-3 s) than in field operation (about $200 \mathrm{~s}$ ) from the initial formation pressure

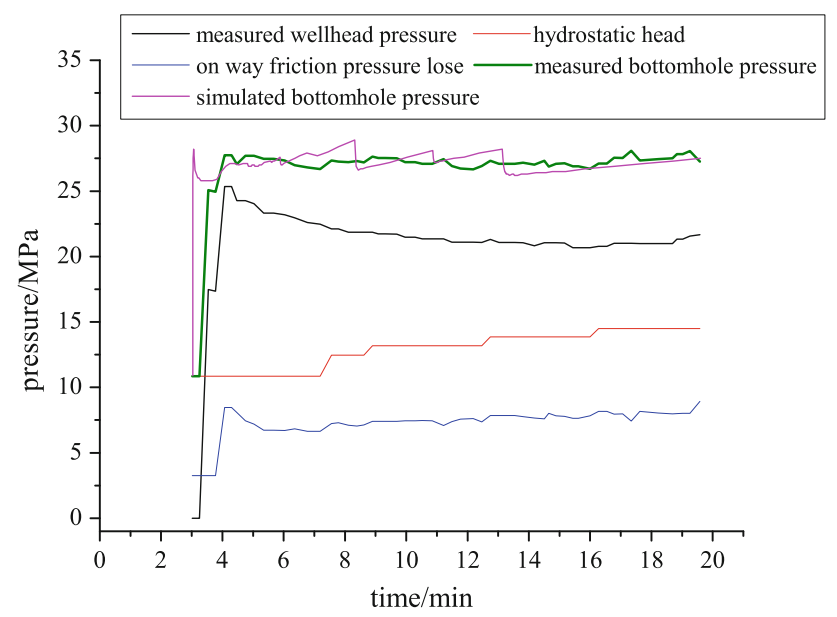

Fig. 4 Field measured and numerical simulation fracturing curves
(10.86 MPa) to the formation breakdown values. Several factors induce the difference: for example, it takes some time for equipments to reach high power, some areas of formation are not completely saturated, micro-fractures in formation exist and there are micro-gaps between cement casing and wellbore.

Figure 5 displays the top view of the horizontal fracture obtained from simulation. It is an ellipse, and not a circle as in the classical radial model. This is caused by perforation direction and difference of in situ stresses in the $X$, $Y$ directions. The color coding in the figure represents the fracture width in the $Z$ direction. With careful observation, it can be found that the maximum width locates at the wellbore (the center of the fracture), and then gradually deceases along the fracture length directions. The unit for the numbers in the figure legend is $\mathrm{m}$.

Figure 6 shows the profiles of the fracture sections as marked in Fig. 5. The meaning of the color coding and the unit of numbers in the figure legend are the same as that in Fig. 5. The width of the fracture is zoomed for clear observation. The maximum width of the fracture is $1.088 \mathrm{~cm}$ located at the wellbore. The total length of the fracture in the $X$ and $Y$ directions is 61.7 and $70.4 \mathrm{~m}$, respectively. The fracture is almost symmetrical about the $Z$ axis in the $Y$ direction (the half length is 35.3 and $35.1 \mathrm{~m}$ in the two sides of the $Z$ axis, respectively), but the symmetry is a little bit lost in the $X$ direction (the half length is 29.2 and $32.5 \mathrm{~m}$ in the two sides of the $Z$ axis, respectively) because of the effect of the initial perforation in this direction.

Figure 7 manifests porous pressure distributions with the color coding in the fracture at about $13 \mathrm{~min}$ of the fracturing process. The unit of the numbers in the figure legend is $\mathrm{Pa}$. The profiles are taken from the section 2-2 of Fig. 5. Figure 7a reveals pressure falling down after the last step extension of fracture and the maximum

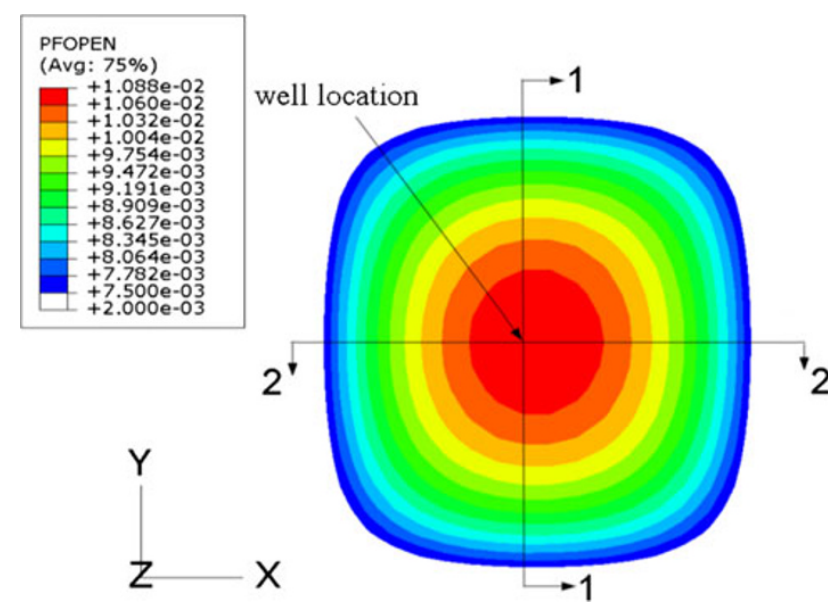

Fig. 5 Top view of the simulation fracture 
Fig. 6 Profiles of the simulation fracture

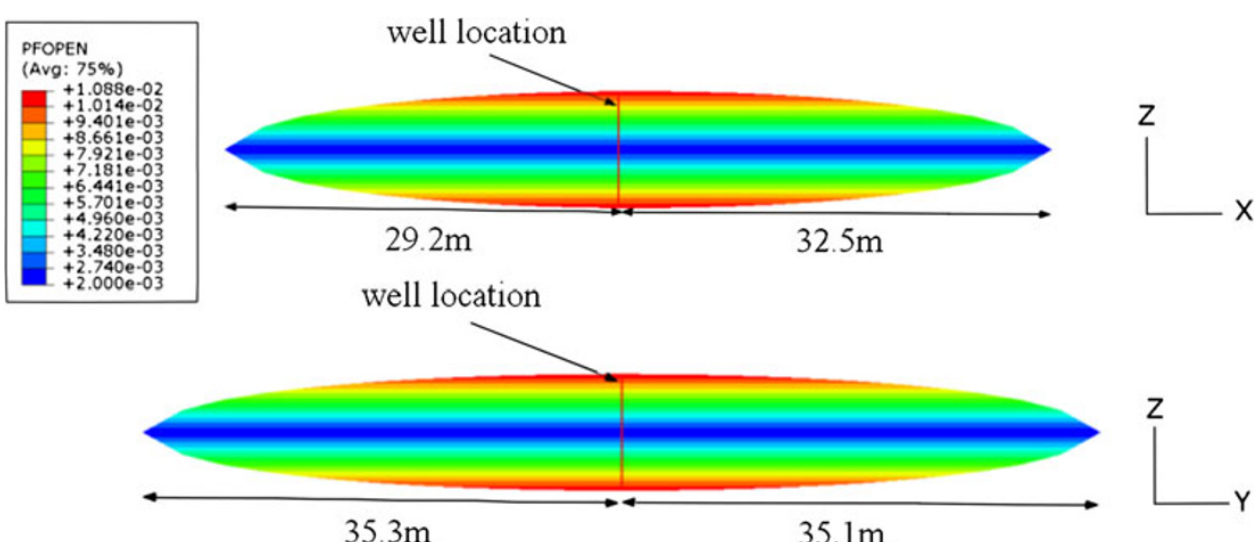

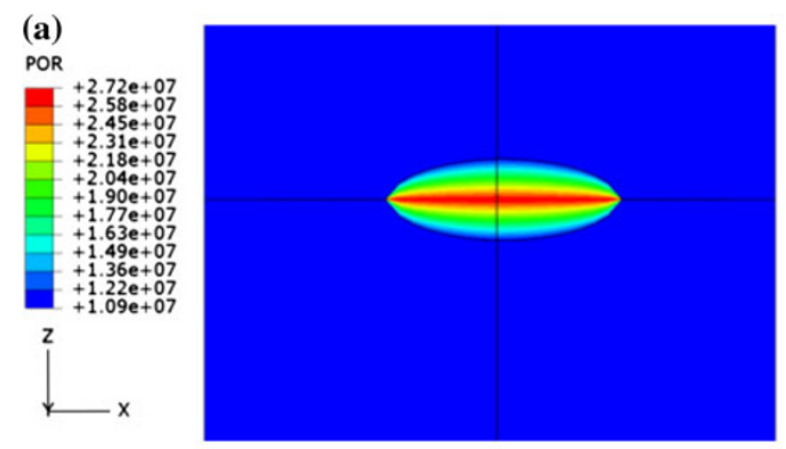

Pressure falling after last step of fracture extension

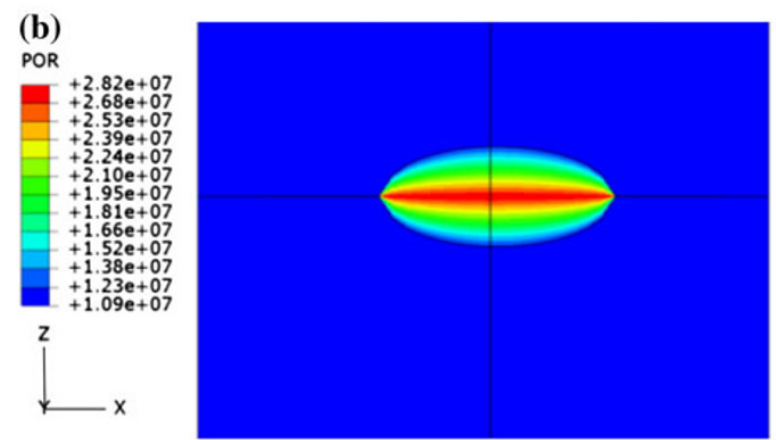

Pressure raising before current step of fracture extension

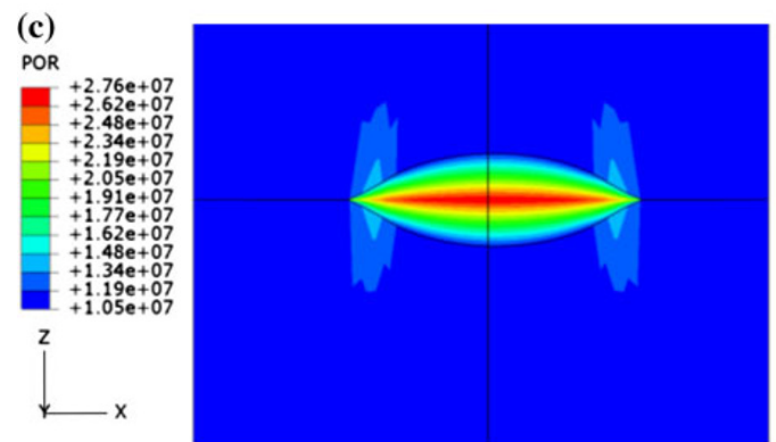

Pressure falling again after current step of fracture extension

Fig. 7 Fracture fluid pressure distributions during fracture propagation pressure in the fracture is $27.2 \mathrm{MPa}$. Before the current step extension of fracture, the pressure in the fracture raises up to $28.2 \mathrm{MPa}$ as shown in Fig. $7 \mathrm{~b}$, and the width of the fracture increases. The tips of the fracture profiles in Fig. 7a, b are both blunt. When the tensile stress around the tip of the fracture reaches the tensile strength of formation, the fracture extends at the current step and the pressure in the fracture falls down to $27.6 \mathrm{MPa}$ as shown in Fig. 7c. The tip of the fracture looks sharper and the maximum width of the fracture decreases a little. Repeating the described processes, the fracture propagates step by step. Propagations of the fracture occur simultaneously in the $X$ and $Y$ directions. The interpretation above coincides with the zigzag curve of simulation as shown in Fig. 4.

\section{Summaries and conclusions}

A 3D non-linear fluid-solid coupling model for horizontal fracturing of vertical well is established with the ABAQUS code. The wellbore, cement casing, perforation, pay layer and the barriers are all included in the model. Fluid-solid coupling elements are used to describe the behavior of formation stress-seepage flow coupling. Initiation and propagation of fracture are simulated with the cohesive element, which is based on damage mechanics. A typical horizontal fracturing process of a vertical well in Daqing Oilfield, China is simulated with the model. The simulated bottom-hole pressure evolution is consistent with the data measured from the field. The correctness of the model is validated. The configurations of the fracture and porous pressure distributions in the fracture are presented and discussed.

Acknowledgments The project was supported by the CNPC Innovation Foundation 
Open Access This article is distributed under the terms of the Creative Commons Attribution License which permits any use, distribution and reproduction in any medium, provided the original author(s) and source are credited.

\section{References}

Adachi J, Siebrits E, Peirce A, Desroches J (2007) Computer simulation of hydraulic fractures. Int J Rock Mech Min Sci 44:739-757

Boone TJ, Detournay E (1990) Response of a vertical hydraulic fracture intersecting a poroelastic formation bounded by semiinfinite impermeable elastic layers. Int J Rock Mech Min Sci Geomech 27(3):189-197

Camanho PP, Dávila CG (2002) Mixed-mode decohesion finite elements for the simulation of delamination in composite materials. NASA/TM-2002-211737

Dean RH, Schmidt JH (2008) Hydraulic fracture predictions with a fully coupled geomechanical reservoir simulator. SPE Annual Technical Conference and Exhibition, 21-24 September 2008, Denver, Colorado, SPE 116470-MS

Deeg WFJ (1999). High propagation pressures in transverse hydraulic fractures: cause, effect and remediation. SPE Annual Technical Conference and Exhibition, 3-6 October 1999, Houston, Texas, SPE 56598

Economides MJ, Nolte KG (2000). Reservoir stimulation. John Wiley \& Sons Ltd, New York, pp 80-90, 160-167

Fragachan FE, Mack MG, Nolte KG and Teggin DE (1993) Fracture characterization from measured and simulated bottomhole pressure. Low Permeability Reservoirs Symposium, 26-28 April 1993, Denver, Colorado, SPE 5848-MS

Hagoort J, Weatherill BD and Settari A (1978) Modeling the propagation of waterflood-induced hydraulic fractures. 1978 SPE Annual Fall Technical Conferences and Exhibition, Houston, Oct $1-4$, SPE 7412
Lord DL, and McGowen JM (1986) Real-time treating pressure analysis aided by new correlation. SPE Annual Technical Conference and Exhibition, 5-8 October 1986, New Orleans, Louisiana, SPE 15367

Malvern LE (1969) Introduction to the mechanics of a continuous medium. Prentice-Hall Inc, NJ, pp 207-215

Marino MA, Luthin JN (1982) Seepage and groundwater. Elsevier Scientific Pub Co, New York, pp 27-32

Maxwell SC, Zimmer U, Gusek R, Quirk D (2009) Evidence of a horizontal hydraulic fracture from stress rotations across a thrust fault. SPE Prod Oper 24(2):312-319

Morales RH, Abou-Sayed AS (1989) Microcomputer analysis of hydraulic fracture behavior with a pseudo-three-dimensional simulator. SPE Prod Eng 4:69-74

Schneider TS, Uldrich DO, Hodge R, Barree B and Martin MW (2007). Horizontal fracture stimulation success in the alpine formation, North Slope, Alaska. SPE Hydraulic Fracturing Technology Conference, 29-31 January 2007, College Station, Texas, SPE 106050-MS

Settari A, Michael CP (1986) Development and testing of a pseudothree-dimensional model of hydraulic fracture geometry. SPE Prod Eng 1(6):449-466

Sneddon N (1946) The distribution of stress in the neighborhood of a crack in an elastic solid. Proc R Soc London A 187:229-260

Turon A, Camanho PP, Costa J, Dávila CG (2006) A damage model for the simulation of delamination in advanced composites under variable-model loading. Mech Mater 38:1072-1089

Willingham JD, Tan HC and Norman LR (1993). Perforation friction pressure of fracturing fluid slurries. Low Permeability Reservoirs Symposium, 26-28 April 1993, Denver, Colorado, SPE 25891

Zhang J, Zhang SC (2004) A study on interference of horizontal fractures of multi-pay layers. J Rock Mech Eng 23(14):23512354 (in Chinese)

Zhang GM, Liu H, Zhang J, Wu HA, Wang XX (2010) Mathematical model and nonlinear finite element equation for reservoir fluidsolid coupling. Rock Soil Mech 31(5):1657-1662 (in Chinese)

Zienkiewicz OC and Taylor RL (2005) The finite element method (5th edition) vol 1, the basis. Elsevier Pte Ltd, London, pp 42-45 